\section{Recent developments centered on orally active iron chelators}

\author{
Robert Hider \\ Institute of Pharmaceutical Science, King's \\ College London, UK
}

\begin{abstract}
Over the past twenty years there has been a growing interest in the orally active iron chelators, deferiprone and deferasirox, both have been extensively studied. The ability of these compounds to mobilize iron from the heart and endocrine tissue has presented the clinician with some advantages over desferrioxamine, the first therapeutic iron chelator. Other orally active iron chelators are currently under development. The critical features necessary for the design of therapeutically useful orally active iron chelators are presented in this review, together with recent studies devoted to the design of such chelators. This newly emerging range of iron chelators will enable clinicians to apply iron chelation methodology to other disease states and to begin to design personalized chelation regimes.
\end{abstract}

\section{Introduction}

Although iron is essential for the proper functioning of all living cells, it is toxic when present in excess. In the presence of molecular oxygen, loosely-bound iron is able to redox cycle between the two most stable oxidation states thereby generating oxygen-derived free radicals such as the hydroxyl radical. ${ }^{1}$ A number of protective strategies are adopted by cells to prevent such damage, including the tight control of iron storage, transport and distribution. ${ }^{2}$ In the normal individual, there is little opportunity for iron-catalyzed free radical generating reactions to occur. However, there are situations when the iron status can change as with genetic hemochromatosis or transfusion-induced iron overload. In such circumstances, the elevated levels of iron ultimately lead to free radicalmediated tissue/organ damage and eventual death. ${ }^{3}$ There is therefore a requirement for the selective removal of iron under such circumstance. Desferrioxamine (DF0; Figure 1A), the most widely used iron chelator in hematology over the past 40 years, has a major disadvantage of being orally inactive. ${ }^{4}$ In order to identify an ideal iron chelator for clinical use, careful design consideration is essential; a range of specifications must be considered such as metal selectivity and affinity, kinetic stability of the complex, bioavailability and toxicity.

\section{Design features for orally active iron chelators}

\section{Metal selectivity}

In designing iron chelators for clinical application, the properties for metal selectivity and resultant ligand-metal complex stability are paramount. Chelating agents can be designed for either the iron(II) or iron(III) oxidation state. High-spin iron(III) is a tripositive cation of radius $0.65 \AA$, and as such forms most stable bonds with ligands such as the charged hydroxamate oxygen atoms as found in DFO. In contrast, the iron(II) cation, which has a lower charge density, prefers chelators containing nitrogen-containing ligands such as 2,2bipyridyl and 1,10-phenanthroline (Figure 2). Ligands that prefer iron(II) retain an appreciable affinity for other biologically important bivalent metals such as copper(II) and zinc(II) ions. In contrast iron(III)-selective ligands, typically oxyanions, are generally more selective for tribasic metal cations over dibasic cations. Most tribasic cations, for instance aluminium(III) and gallium(III), are not essential for living cells and thus in practice iron(III) provides the best target for iron chelator design under biological conditions. ${ }^{5}$ Catechols, hydroxamates and hydroxypyridinones are highly selective for iron(III) (Figure 2). In contrast 8-hydroxyquinolines have similar affinities for both iron(III) and iron(II).

\section{Thermodynamic stability of iron(III) complexes}

The coordination requirements of high spin iron(III) are best satisfied by six donor atoms ligating in an octahedral fashion to the metal center, the affinity for the ligand generally decreasing in the sequence; hexadentate $>$ tridentate $>$ bidentate $^{5}$ (Figure 3 ). Thus generally a hexadentate trihydroxamate such as DFO (Figure 1A) will bind iron(III) much move tightly than the corresponding bidentate hydroxamate, acetohydroxamic acid (Figure 1B). Under biological conditions, a comparison standard which is generally more useful than the stability constant is the $\mathrm{pFe}^{3+}$ value. ${ }^{6} \mathrm{pFe}^{3+}$ is defined as the negative logarithm of the concentration of the free iron(III) in solution. Typically $\mathrm{pFe}^{3+}$ values are calculated for total [ligand] $=10^{-5} \mathrm{M}$, total [iron] $=10^{-6} \mathrm{M}$ at $\mathrm{pH}$ 7.4. The comparison of ligands under these conditions is useful, as the $\mathrm{pFe}^{3+}$ value, unlike the stability constants $\log \mathrm{K}$ or $\log \beta_{3}$, takes into account the effects of ligand protonation and denticity as well as differences in metal-ligand stoichiometries. The comparison of the $\mathrm{pFe}^{3+}$ values for hexadentate and bidentate ligands reveals that hexadentate ligands are far superior to their bidentate counterparts under typical in vivo conditions. The values for DFO and acetohydroxamic acid being
Correspondence: Robert Hider, Institute of Pharmaceutical Science, King's College London, 150 Stamford Street, London, SE1 9NH, United Kingdom.

E-mail: robert.hider@kcl.ac.uk

Key words: active iron chelators, deferiprone, deferasirox, desferrioxamine, recent studies.

Received for publication: 29 January 2014

Accepted for publication: 19 March 2014.

This work is licensed under a Creative Commons Attribution 3.0 License (by-nc 3.0).

CCopyright R. Hider, 2014

Licensee PAGEPress, Italy

Thalassemia Reports 2014; 4:2261

doi:10.4081/thal.2014.2261

25 and 13 respectively. The higher the $\mathrm{pFe}^{3+}$ value, the greater the affinity for iron(III).

\section{Distribution of chelator}

In order for a chelating agent to exert its pharmacological effect, a drug must be able to reach the target sites at sufficient concentration. Hence the key property for an orally active iron chelator is its ability to be efficiently absorbed from the gastrointestinal tract and to cross biological membranes thereby gaining access to the desired target sites such as the liver.

In order to achieve efficient oral absorption, the chelator should possess appreciable lipid solubility which may facilitate the molecule to penetrate the gastrointestinal tract (partition coefficient between n-octanol and water greater than 0.2). ${ }^{7}$ Molecular size is also a critical factor which influences the rate of drug absorption. ${ }^{8}$ Non-facilitated diffusion by the transcellular route involves diffusion into the small intestine enterocyte and falls off rapidly with molecular weight $>500 .^{9}$ This molecular-weight limit provides a considerable restriction on the choice of chelator and may effectively exclude hexadentate ligands from consideration, most siderophores, for instance DFO, have molecular weights in the range 500-900. In contrast bidentate and tridentate ligands, by virtue of their much lower molecular weights, tend to possess higher absorption efficiencies.

\section{Toxicity of chelators and their iron complexes}

The toxicity associated with iron chelators originates from a number of factors; including inhibition of metalloenzymes; lack of metal selectivity, redox cycling of iron-complexes between iron(II) and iron(III), thereby generating free radicals and the kinetic lability of the iron-complex leading to iron redistribution. 


\section{Enzyme inhibition}

In general, iron chelators do not directly inhibit heme-containing enzymes due to the inaccessibility of porphyrin-bound iron to chelating agents. In contrast many non-heme iron-containing enzymes such as the lipoxygenase and aromatic hydroxylase families and ribonucleotide reductase are susceptible to chelator-induced inhibition. ${ }^{10}$ Lipoxygenases are generally inhibited by hydrophobic chelators, therefore, the introduction of hydrophilic characteristics into a chelator tend to minimize such inhibitory potential. Stereochemistry can also limit chelator access to the metal binding center and the introduction of rigid side chain close to the chelating center of the molecule can reduce inhibitory properties. ${ }^{11}$ Thus careful control of the bulk and shape of iron chelators leads to minimal inhibitory influence on many metalloenzymes.

\section{Metal selectivity}

An ideal iron chelator should be highly selective for iron(III) in order to minimize chelation of other biologically essential metal ions, which could lead to deficiency with prolonged usage. Unfortunately, many ligands that possess a high affinity for iron(III) may also have appreciable affinities for other metals such as zinc(II), this being especially so with carboxylate- and nitrogen-containing ligands. However, this is less of a problem with the catechol, hydroxamate and hydroxypyridinone ligand families which possess a strong preference for tribasic over dibasic cations.

\section{Iron-complex structure and redox activity}

In order to prevent free radical production, iron should be coordinated in such a manner as to avoid direct access of oxygen and hydrogen peroxide, and to possess a redox potential which cannot be reduced under biological conditions. Most hexadentate ligands with oxygen containing ligands such as DFO form iron complexes (Figure 4) which are kinetically inert and reduce hydroxyl radical production to a minimum by failing to redox cycle. In contrast bidentate and tridentate ligands are kinetically more labile and the corresponding iron(III) complexes can dissociate at low ligand concentrations. However at such low concentrations $(\leq 5 \mu \mathrm{M})$ there is minimal hydroxyl radical production. $^{12}$

Chelators that are capable of binding both iron(II) and iron(III) at neutral $\mathrm{pH}$ values redox cycle. This is an undesirable property for iron scavenging molecules, as redox cycling can also lead to the production of reactive oxygen radicals (Figure 5). Significantly the high selectivity of siderophores for iron(III) over iron(II) renders redox cycling under biological conditions unlikely. Thus the redox potential of the iron complex of desferrioxamine is low, namely -
$468 \mathrm{mV}{ }^{13}$ Iron complexes with redox potentials above $-200 \mathrm{mV}$ are likely to redox cycle under

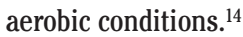

\section{Kinetic lability of iron complexes}

Hexadentate ligand iron complexes tend to be inert, the rate of dissociation of the complex being vanishingly small at neutral $\mathrm{pH}$ values. This renders such molecules ideal scavengers of iron. In contrast bidentate and tridentate ligands are less kinetically stable and are able to dissociate at appreciable rates, thereby possibly facilitating iron redistribution. Such a property is undesirable for most therapeutic applications, where efficient iron excretion is required. In order to avoid appreciable redistribution of iron in mammalian body tissues, chelators possessing a high iron(III) affinity are required, generally a pFe ${ }^{3+}$ value $\geq 20$ appears to be sufficient to minimize the redistribution of iron in most situations. ${ }^{5}$

\section{Ability to scavenge non-trans- ferrin bound iron}

Under normal conditions, serum transferrin is $20-35 \%$ saturated with iron and this is the only major form of non-heme iron in plasma. However, under conditions of iron overload, transferrin becomes saturated and an appreciable proportion of iron released by the reticuloendothelial system is therefore unable to bind to transferrin and so remains in the form of non-transferrin bound iron (NTBI). ${ }^{15}$ The speci-
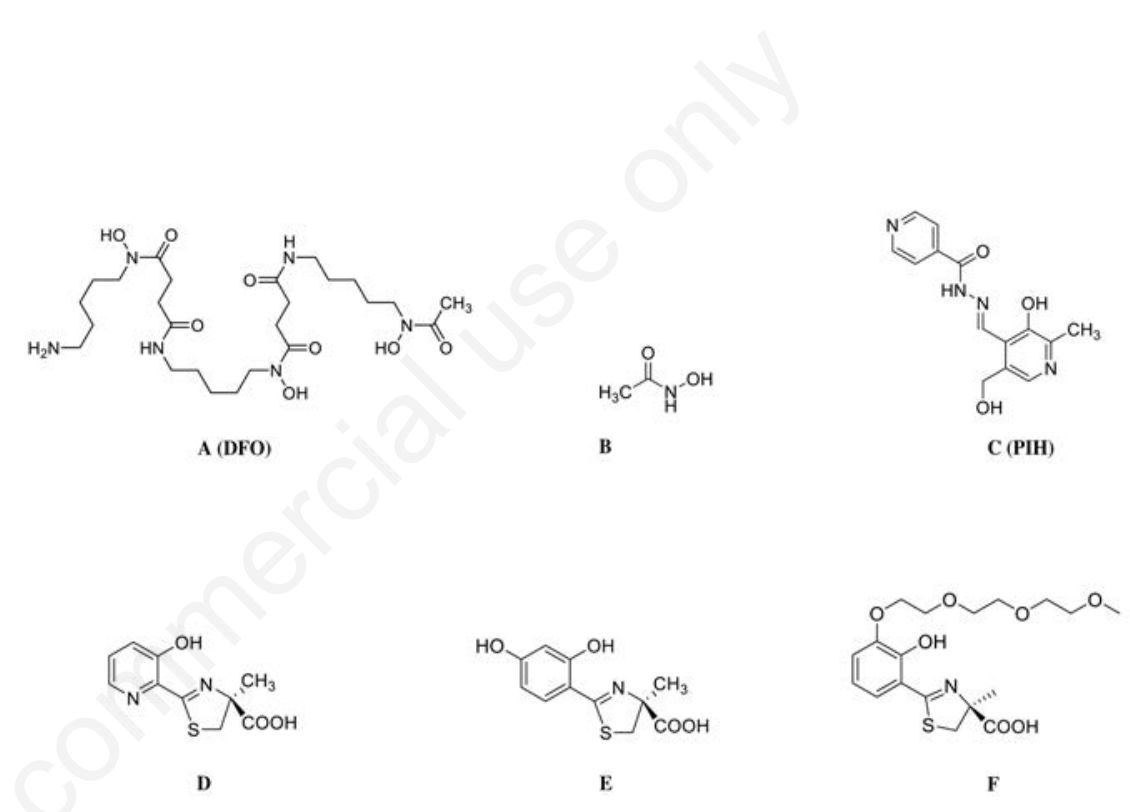

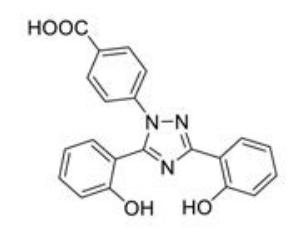

G

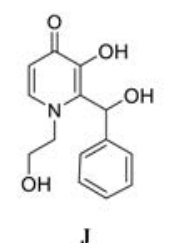

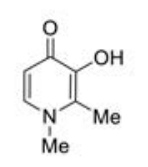

H

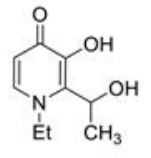

K

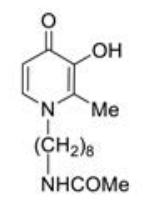

I

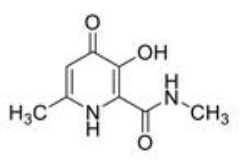

L.

Figure 1. Structures: A) desferrioxamine (DFO); B) acetohydroxamic acid; C) pyridoxal isonicotinoyl hydrazone (PIH); D) desferrithiocin; E) deferitrin; F) deferitazole; G) deferasirox; H) deferiprone; I) CM1; J) CGP65015; K) CP365; L) CP511. 
ation of this iron pool is complicated, but dominated by citrate and albumin. ${ }^{16,17}$ NTBI is taken up by cells independently of the transferrin receptor. Thus highly vascular tissues, for instance endocrine tissue and heart muscle become iron loaded. The resulting hydroxyl radical generation in iron loaded cells leads to severe damage and eventually cell death. Transferrin also contributes to defence against infection by depriving microorganisms of an iron supply. ${ }^{18}$ Thus the presence of NTBI presents a weakness, rendering the host more susceptible towards infection. For these reasons it is probably best to remove all traces of NTBI throughout the entire day. Ideally a therapeutic chelator should be able to scavenge iron from this pool. By maintaining a suitable blood chelator level for $24 \mathrm{~h}, 7$ days per week, the NTBI level can be permanently reduced to zero.

\section{Tridentate iron(III) chelators}

Tridentate ligands fall into two major classes, the $\mathrm{Y}$ class, where $\mathrm{X}$ can be oxygen, sulfur or nitrogen (NH) and the $\mathrm{W}$ class, where $\mathrm{X}$ can be oxygen, sulfur or nitrogen ( $\mathrm{NH}$ ) but $\mathrm{Z}$ is limited to nitrogen (Figure 6). The major difference between these two classes is that with the $\mathrm{W}$ class, $\mathrm{Z}$ acts both as a ligating group and part of the linking chain. ${ }^{19}$ This renders it possible to involve smaller chelating rings and therefore reduce any adverse changes in entropy associated with the complexation of iron(III). ${ }^{20}$ The smaller molecular size also influences oral bioavailability. However for optimal selectivity for iron(III), the three coordinating groups should be anionic oxygen (vide infra), which excludes the $\mathrm{W}$ class. In order to design tridentate ligands of the ideal W class, it is necessary to include a nitrogen-containing moiety in the central position $(\mathrm{Z})$. The presence of nitrogen can have the adverse effect of rendering the iron(III) complex more easily reduced and therefore more susceptible towards redox cycling. Furthermore, the presence of two nitrogens in the coordination sphere of a $2: 1$ iron(III) complex (Figure 3 ) reduces the selectivity of iron(III) over zinc(II). 19,21,22

\section{Pyridoxal isonicotinoyl hydrazone}

Pyridoxal isonicotinoyl hydrazone (PIH; Figure 1C) was initially identified as an iron chelator by Ponka and coworkers. ${ }^{23}$ Subsequent studies demonstrated that $\mathrm{PIH}^{24,25}$ and analogues ${ }^{26}$ were effective at scavenging and causing the excretion of iron in a range of in vivo models. However only modest iron excretion was demonstrated in clinical trials. ${ }^{27}$ Many PIH analogues have also been investigated, ${ }^{28}$ but studies in cebus monkeys disclosed appreciable toxicity which has precluded the use of these chelators for clinical purposes. ${ }^{29}$ The redox potential of the 2:1 iron/PIH complex is +130 $\mathrm{mV}$ and so this complex is predicted to redox cycle under physiological conditions.

\section{Desferrithiocin}

Desferrithiocin (DFT) (Figure 1D) is a siderophore isolated from Streptomyces antibi-

Chelators selective for iron(III)<smiles>Oc1ccccc1O</smiles><smiles>[R]C(=O)N([R2])O</smiles>

Catechol<smiles>[R]n1ccc(=O)c(O)c1</smiles>

Pyridinone

Chelators selective for iron(II)<smiles>c1ccc(-c2ccccn2)nc1</smiles>

Bipyridine oticus. It forms a 2:1 complex with iron(III) at neutral pH using a phenolate oxygen, a carboxylate oxygen and a nitrogen atom as ligands. ${ }^{30} \mathrm{It}$ possesses a high affinity for ferric iron (log $\beta_{2}=29.6$ ), however, by virtue of the presence of the nitrogen and carboxylate ligands, it also binds zinc relatively tightly $\left(\log \beta_{2}=15.3\right)$. Long

\section{Chelators with high affinity for both iron(III) and iron(II)}<smiles>Oc1cccc2cccnc12</smiles><smiles>Nc1ccccc1O</smiles>

Hydroxyquinoline

Aminophenol

Figure 2. Simple iron chelators.<smiles></smiles>

Bidentate ligand 3:1 complex

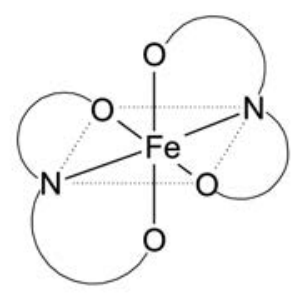

Tridentate ligand

2:1 complex

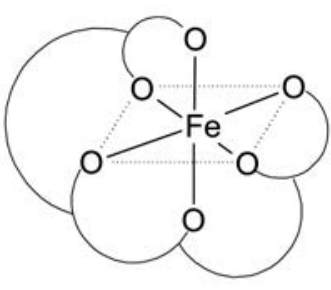

Hexadentate ligand

1:1 complex

Figure 3. Schematic representation of chelate ring formation in metal-ligand complexes. 
term studies of DFT in normal rodents and dogs at low doses have shown toxic side effects, such as reduced body weight and neurotoxicity. ${ }^{31}$ The redox potential of DFT is $-270 \mathrm{mV}$, close to the critical level of $-200 \mathrm{mV}$ (vide supra). Indeed the iron complex of DFT has been demonstrated to be toxic. ${ }^{32}$ A range of synthetic analogues of DFT have been prepared in an attempt to design molecules lacking renal and neurotoxicity 33,34 and two such molecules have been identified, namely deferitrin (Figure 1E) and deferitazole (Figure 1F). Deferitrin (Figure 1E), was found to be highly effective when given orally to rats and primates. ${ }^{35}$ Histopathological analysis indicated some nephrotoxicity but much less than that arising from DFT. ${ }^{36}$ Phase I clinical trials demonstrated good oral absorption, however the compound was not progressed beyond Phase II clinical trials due to nephrotoxicity. ${ }^{37}$ Deferitazole (Figure 1F) also binds iron(III) with high affinity ${ }^{38}$ and in contrast to deferitrin (Figure 1E), demonstrated no observable toxicity at a predicted dose level range in preclinical studies. The compound has entered clinical trials sponsored by Shire, ${ }^{39}$ where it has been shown to be well tolerated and to possess favorable pharmacokinetics. Deferitazole is currently in Phase II clinical trials.

The chemical modifications associated with the transformation of DFT (Figure 1D) to deferitazole (Figure 1F) leads to a decrease in redox potential of the respective iron complexes. Thus the redox potential of deferitazole (Figure 1F) is $-322 \mathrm{mV},{ }^{38}$ a sufficiently negative value to render redox cycling under physiological conditions to be difficult. ${ }^{14}$

\section{Triazoles}

Triazoles have been investigated as ligands by Novartis. ${ }^{40-42}$ These molecules chelate iron(III) with two phenolate oxygens and one triazolyl nitrogen. The lead compound deferasirox (Figure 1G) possesses a $\mathrm{pFe}^{3+}$ value of 22.5 and is extremely hydrophobic, with a log $P_{\text {water/octanol }}$ value of 3.8 and a $\log D_{7.4}$ value of $1.0 .^{42}$ As a result, it can penetrate membranes easily and possesses good oral availability. Indeed, when orally administered to hypertrans-

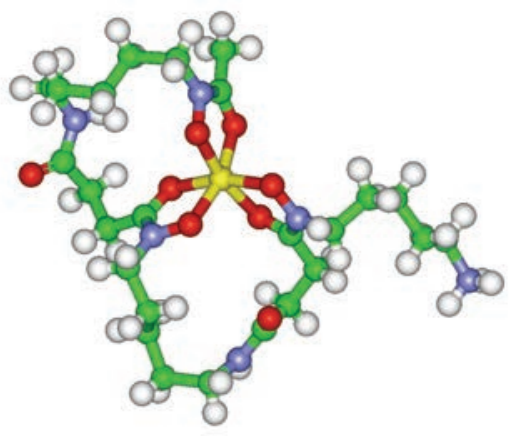

Figure 4. Ferrioxamine B ( $\Lambda$-C-trans,trans conformation).

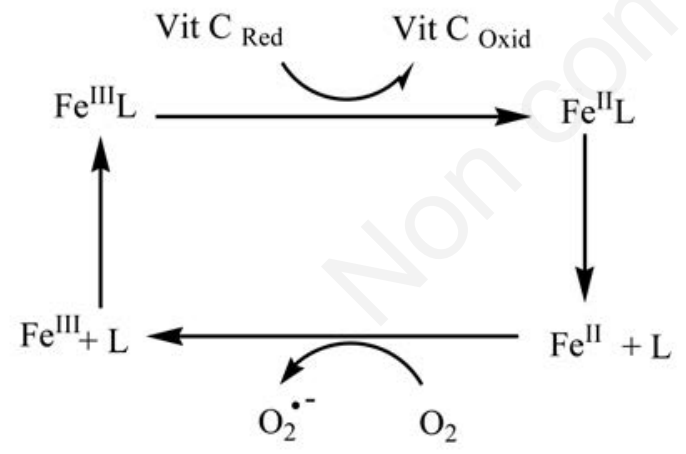

Figure 5. Redox cycling of an iron complex.
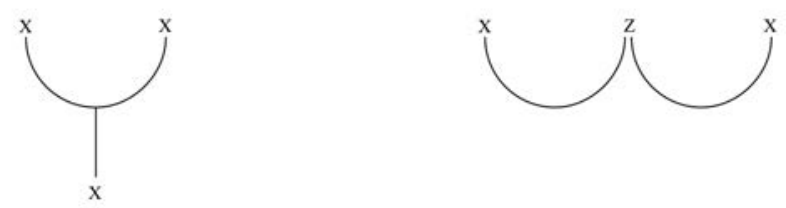

Y class

W class

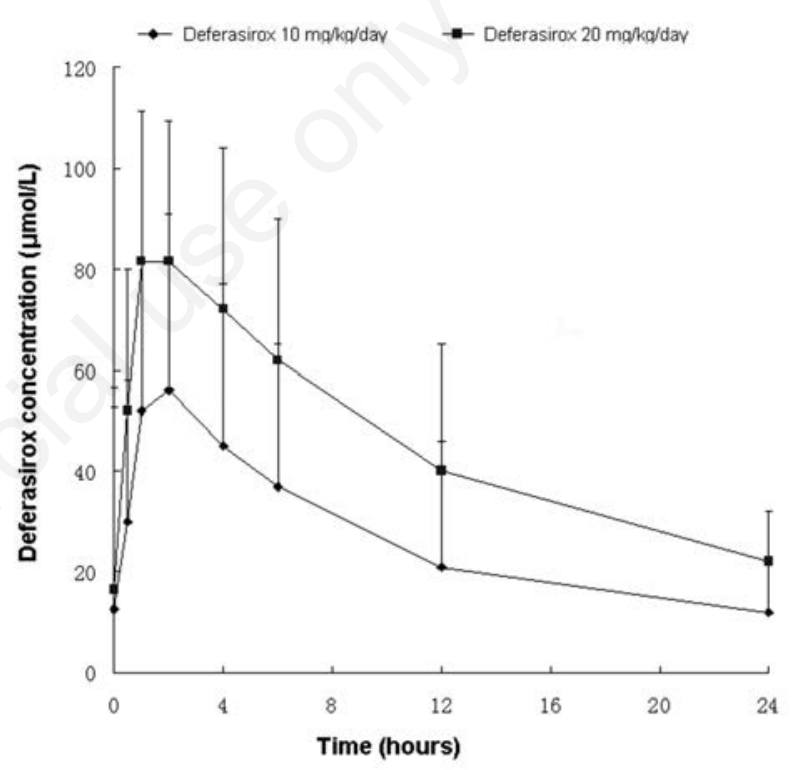

Figure 7. Mean plasma concentrations of deferasirox following a dose of 10 or $20 \mathrm{mg} / \mathrm{kg} /$ day.

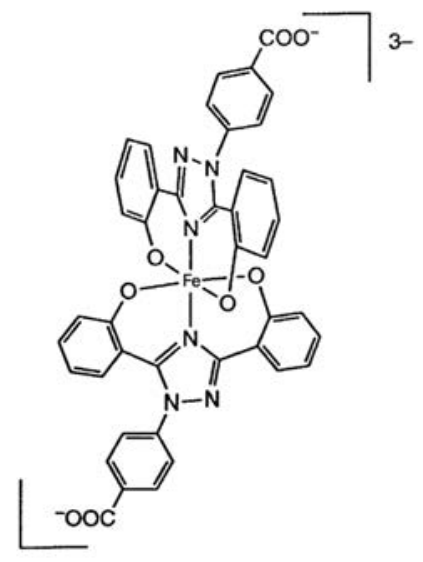

Figure 8. Iron(III) complex of deferasirox.
Figure 6. The design of tridentate ligands. 
fused rats, deferasirox promotes the excretion of chelatable iron from hepatocellular iron stores four to five times more effectively than DFO. ${ }^{43}$ By virtue of a high proportion of both the free ligand and the 2:1 iron complex binding to albumin (greater than 99\%), ${ }^{44}$ the ligand possesses low toxicity despite its strong lipophilic character. The ability to bind to albumin also offers an explanation for the finding that deferasirox-induced iron excretion occurs mainly in the feces, with little iron being present in the urine.

The extreme hydrophobicity of this chelator necessitates formulation in dispersion tablets, containing three disintegrants, sodium dodecyl sulphate, povidone and crospovidone. Thus deferasirox is typically given once daily each morning as a dispersed solution in water, half an hour before breakfast. Even with this single dose deferasirox (Figure 1G) remains in the circulation for $24 \mathrm{~h}$ (Figure 7) ${ }^{45}$ and thus has the potential to maintain extremely low NTBI levels for $24 / 7$. Deferasirox has been demonstrated to be efficient at removing liver iron from regularly transfused patients $\mathrm{s}^{46,47}$ but is apparently less effective at removing cardiac iron. ${ }^{48}$ Deferasirox forms a 2:1 iron complex (Figure 8) which possesses a net charge of $3^{-}$and a molecular weight over 800 . Should such a complex form intracellularly, it is possible that the iron will remain trapped in the cell, offering a possible explanation for the relative inefficiency of this chelator to remove iron from the heart.

Although the iron complex of deferasirox contains two nitrogen atoms in the iron coordination sphere (Figure 8), the redox potential of this complex is $-600 \mathrm{mV},{ }^{49}$ confirming that the iron complex will not redox cycle under physiological conditions. Critical steric factors are responsible for this surprisingly low redox potential. With an entirely planar tridentate conformation of deferasirox, the metal-oxygen bond is limited to the short length of $1.6 \AA$ and only very small cations are capable of forming such M-0 bonds. ${ }^{49}$ The ionic radius of iron(III) is $0.65 \AA$, whereas those of iron(II), copper(II) and zinc(II) are $0.78,0.73$ and 0.74 A respectively. Thus whereas iron(III) can be accommodated in a 2:1 complex, where the three coordinating atoms are located on an almost coplanar frame work (Figure 8), iron(II) cannot and in this redox state the metal can only be accommo- dated by out of plane twisting of the two coordinating phenol rings, destroying the coplanarity of the coordinating center, thereby reducing the affinity for iron(II). The same situation holds for copper(II) and zinc(II), indeed these two metals form a different type of complex with desferasirox. The triazole class of chelator can exist in two conformations, the tridentate conformation (Figure 9A) or the bis-bidentate conformation (Figure 9B). Copper(II) and zinc(II) have preference for the less strained bis-bidentate conformation, thereby forming polymeric complexes, which precipitate from aqueous solution. ${ }^{42,50}$

As with all therapeutic iron chelators there are side effects associated with deferasirox, ${ }^{47,51}$ kidney toxicity being particularly prevalent. ${ }^{52,53}$

\section{Bidentate iron(III) chelators}

Bidentate ligands form 3 complex types with iron(III), the 1:1, 2:1 and 3:1 complexes (Figure 10). To ensure minimal toxicity and maximal iron scavenging, it is desirable for the $3: 1 \mathrm{com}$ -

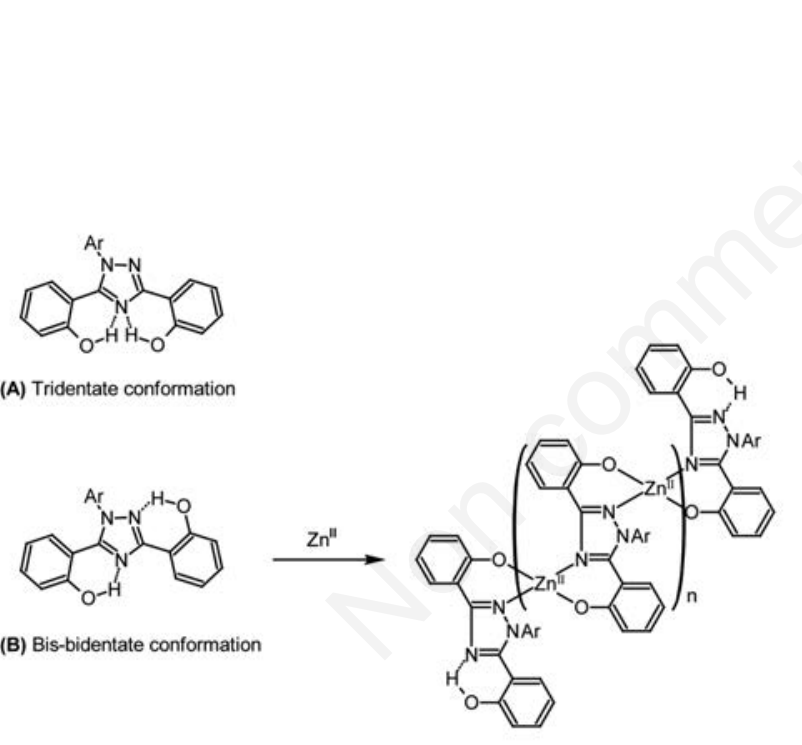

Figure 9. Two possible conformations of the triazole derivatives: (A) the tridentate conformation and (B) the bis-bidentate conformation. The bis-bidentate structure has a strong tendency to form polymeric complexes.

$$
\left[\mathrm{Fe}^{\mathrm{IIII}}\right]^{3+}+\mathrm{LH} \stackrel{\mathrm{H}^{+}}{\longleftarrow}\left[\mathrm{Fe}^{\mathrm{III}} \mathrm{L}\right]^{2+} \stackrel{\mathrm{LH} \mathrm{H}^{+}}{\longleftarrow}\left[\mathrm{Fe}^{\mathrm{III}} \mathrm{L}_{2}\right]^{+} \stackrel{\mathrm{LH} \mathrm{H}}{\longleftarrow}\left[\mathrm{Fe}^{+} \mathrm{HI}_{3}\right]^{0}
$$

Figure 10. Formation of 3 different iron complexes formed from iron(III) and the bidentate ligand (L).

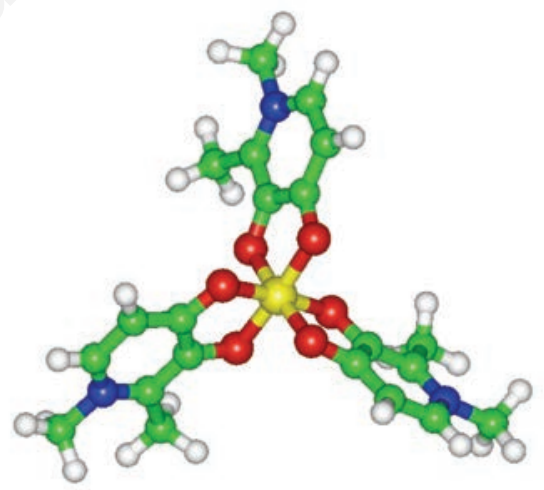

Figure 11. 3:1 iron(III) complex of 1,2-dimethyl-3-hydroxypyridin-4-one.

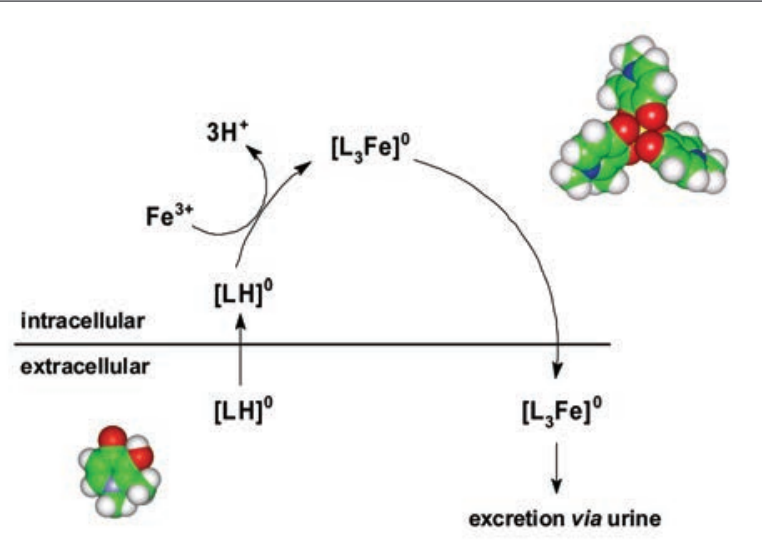

Figure 12. Schematic representation of the penetration of deferiprone $[\mathrm{LH}]^{\circ}$ through the plasma membrane. The bidentate ligand scavenges loosely bound intracellular iron, forming the 3:1 complex which also carries zero net charge. Efflux as the iron complex leads to iron excretion. 
plex to dominate at $\mathrm{pH} 7.4$. There is a wide range of iron(III) binding bidentate ligands (Table 1) but only a few are associated with a dominant 3:1 complex at neutral pH values. These are the three compounds which possess a $\mathrm{pFe}^{3+}$ value greater than 20 , namely the teraphthamide, ${ }^{54}$ the pyridine-4-one, ${ }^{55,56}$ and 8-hydroxyquinoline..$^{57}$ The teraphthalamide forms a 3:1 trinegative iron complex, which in principle will become trapped inside cells on scavenging iron. This series of compounds has not been investigated for their potential as orally active iron chelators, but they hold considerable potential as constituent subunits for multidentate chelators. ${ }^{54} 8$-hydroxyquinoline also possesses a relatively high affinity for iron(II), resulting with a redox potential of $-150 \mathrm{mV} .^{58}$ This value is indicative of a tendency to redox cycle under biological conditions and iron complexes of this ligand have been demonstrated to be toxic. ${ }^{59}$ In contrast the pyridine-4-one class yield noncharged 3:1 complexes (Figure 11), which depending on hydrophobicity and molecular size can efflux from cells by non facilitated diffusion. ${ }^{5}$ To date this is the only bidentate class to have been subjected to extensive clinical study.

\section{Dialkylhydroxypyridinones}

The 1,2-dimethyl derivative (deferiprone, L1, CP20) (Figure 1H) is marketed by Apotex Inc., Toronto, Canada as Ferriprox ${ }^{\mathrm{TM}}$. Deferiprone was first reported as a potential orally active iron chelator in $1984^{55}$ and demonstrated to be active in man in $1987 .{ }^{60}$ It was licensed for use in India in 1994 and in Europe in 1999, receiving full marketing authorization in 2002. The FDA provided approval for its use in 2011. There are numerous reports indicating the comparative effectiveness of desferrioxamine and deferiprone. ${ }^{61,62}$ A particularly important property of deferiprone is its ability to penetrate cells, coordinate iron, forming a neutral complex, which is also capable of permeating membranes. Thus, iron can be readily removed from iron-loaded cells including those of cardiac tissue (Figure 12$)^{63}$ and this ability extends to the clinical situation, where it has been directly demonstrated that deferiprone therapy is asso- ciated with significantly greater cardiac protection than DFO (Figure 1A) in patients with thalassemia major. ${ }^{64-66}$ Unfortunately, the dose required to keep a previously well chelated patient in negative iron balance with deferiprone is relatively high, in the region of $75-100 \mathrm{mg} \mathrm{kg}^{-1}$ day $^{-1}{ }^{167}$ One of the major reasons for the limited efficacy of deferiprone in clinical use is that it undergoes extensive metabolism in the liver. The 3-hydroxyl functionality, which is crucial for scavenging iron, is a prime target for glucuronidation. Urinary recovery studies conducted on deferiprone in man has shown that, $>85 \%$ of the administered dose is recovered in the urine as the non-chelating 3-0-glucuronide conjugate. ${ }^{68}$ The use of deferiprone has a range of associated side effects, ${ }^{69,70}$ the most important being a low incidence of reversible agranulocytosis. ${ }^{71}$ A closely related pyridinone has been developed by the Chiang Mai group (Thailand), namely CM1 (Figure 1I). ${ }^{72}$ The chelator is orally active in the rat and relatively nontoxic. CM1 is currently being subjected to systematic toxicity studies.

Table 1. pKa values and affinity constants for iron-binding bidentate ligands (data sourced from references: ${ }^{54,56,90}$ ).

\begin{tabular}{|c|c|c|c|c|c|}
\hline Ligand & Structure & $\mathrm{pKa}_{1}$ & $\mathrm{pKa}_{2}$ & $\log \beta_{3}$ & $\mathrm{pFe}^{3+}$ \\
\hline N-N'-dimethyl-2,3-dihydroxybenzamide & & 8.4 & 12.1 & 40.2 & 15 \\
\hline 2,3-dihydroxy-N,N'-dimethylteraphthalamide & & 6.1 & 11.1 & 41.8 & 21.1 \\
\hline Acetohydroxamic acid & & - & 9.4 & 28.3 & 13 \\
\hline Maltol & & - & 8.7 & 28.5 & 15 \\
\hline 1-hydroxypyridin-2-one & & - & 5.8 & 27 & 16 \\
\hline 1,2-dimethyl-3-hydroxy pyridin-4-one & & 3.6 & 9.9 & 37.2 & 20.5 \\
\hline 8-hydroxyquinoline & & 4.8 & 9.7 & 36.9 & 20.6 \\
\hline
\end{tabular}


Table 2. Efficacy of 3-hydroxypyridin-4-ones.

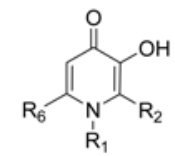

\begin{tabular}{lccccc} 
Chelator & $\mathrm{R}_{1}$ & $\mathrm{R}_{2}$ & $\mathrm{R}_{6}$ & $\mathrm{pFe}^{3+}$ & Efficacy (\%)* \\
Deferiprone $^{\circ}$ & $\mathrm{CH}_{3}$ & $\mathrm{CH}_{3}$ & $\mathrm{H}$ & 20.5 & 9.5 \\
CP365 & $\mathrm{CH}_{2} \mathrm{CH}_{3}$ & $\mathrm{CH}(\mathrm{OH}) \mathrm{CH}_{3}$ & $\mathrm{H}$ & 21.4 & 50.6 \\
\hline $\mathrm{CP} 502^{\#}$ & $\mathrm{CH}_{3}$ & $\mathrm{CONHCH}_{3}$ & $\mathrm{CH}_{3}$ & 21.7 & 54.8 \\
\hline
\end{tabular}

*Iron mobilization efficacy of chelators $(450 \mu \mathrm{mol} / \mathrm{kg})$ was measured using the ${ }^{59} \mathrm{Fe}$-ferritin loaded rat model $;{ }^{76,77}{ }^{\circ}$ see structure in Figure $1 \mathrm{H}$; ${ }^{\sharp}$ see structure in Figure $1 \mathrm{~L}$.

\section{High iron affinity hydroxypyridinones}

In order to further improve chelation efficacy, considerable effort has been applied to the design of novel hydroxypyridinones with enhanced $\mathrm{pFe}^{3+}$ values. $^{73}$ Novartis (previously Ciba) synthesized a range of bidentate hydroxypyridinone ligands, which possess an aromatic substituent at the 2-position. The lead compound (Figure 1J) was found to be orally active ${ }^{74}$ and highly effective at removing iron from both the iron-loaded rat ${ }^{74}$ and marmoset. ${ }^{75}$ In similar fashion, Hider and coworkers have demonstrated that the introduction of either a 1-hydroxyalkyl group (Figure $1 \mathrm{~K})^{76}$ or an amido function (Figure 1L) ${ }^{77}$ at the 2-position of 3-hydroxypyridin-4-ones enhances the affinity for iron(III) over the pH range 5-8. Although such an effect reduces the overall iron(III) stability constant, it reduces the pKa value of the chelating function by a larger margin. These combined changes result in an increase in the corresponding $\mathrm{pFe}^{3+}$ values ${ }^{75-77}$ due to the reduced competition with hydrogen ions; thus the 2amidopyridin-4-one (Figure 1L) has a pFe value of 21.7 as compared with that of the analogous deferiprone (Figure $1 \mathrm{H}$ ), which possesses a pFe value of 20.5. In practical terms this means that at $\mathrm{pH} 7.4$ (Figure 1L) binds iron over ten times more tightly than deferiprone. Interestingly, the Novartis lead compound (Figure 1J) also possesses a 1-hydroxyl group at the 2-position and this is almost certainly responsible for the observed enhanced $\mathrm{pFe}^{3+}$ value.

These novel high $\mathrm{pFe}^{3+} \mathrm{HPOs}$ show promise in their ability to remove iron under in vivo conditions (Table 2). ${ }^{77}$ Detailed dose-response studies suggest that chelators with high $\mathrm{pFe}^{3+}$ values scavenge iron more effectively at lower doses when compared with simple dialkyl substituted hydroxypyridinones and so in principle can be used at lower doses. Several of these compounds are the subject of preclinical evaluation.

\section{Combined therapy with desferrioxamine and hydroxypyridinones}

By virtue of its small size and ability to penetrate cells, deferiprone has the capability of efficiently scavenging excess iron. However by virtue of its bidentate nature, the ability of deferiprone for iron(III) at neutral $\mathrm{pH}$ values is highly concentration dependant and at relatively low concentrations $(<5 \mu \mathrm{M})$ the iron deferiprone complex will donate iron to competing ligands. ${ }^{78}$ Thus in principle there is a tendency for deferiprone to redistribute iron. ${ }^{79}$ If deferiprone is used together with a high affinity hexadentate chelator such as desferrioxamine, the deferiprone iron complex will readily donate iron to the kinetically more stable desferrioxamine. ${ }^{80}$ Indeed, deferiprone enhances plasma NTBI removal in the presence of desferrioxamine. ${ }^{81}$ Early clinical studies indicated that such combination therapy is effective at increasing iron excretion..$^{82,83}$ These observations led to more extensive clinical investigations using deferiprone and desferrioxamine in sequential fashion and resulted with beneficial effects in survival, iron removal and cardiac disease..$^{84-89}$

Recently successful chelation therapy using both deferasirox and deferiprone has been reported. ${ }^{89}$

\section{Conclusions}

Over the past decade the introduction of two orally active iron chelators, deferiprone and desferairox has simplified iron chelation therapy and rendered the treatment more widely available. There are other orally active chelators under development and so it is likely that in years to come clinicians will have a choice of a range of such molecules, rendering it possible to optimize such therapy for individuals. Combination therapy may become possible for two orally active chelators; at present, combination therapy with desferoxamine and deferiprone is reported to be the most effective treatment for many patients. ${ }^{87}$ The combined therapy procedure is likely to enhance iron excretion, target specific iron compartments, minimize side effects (by virtue of the use of lower doses), facilitate individualization of therapy and improve compliance.

\section{References}

1. Halliwell B, Gutteridge JMC. Free radicals in biology and medicine, 3rd ed. Oxford: Oxford University press; 1998.

2. Crichton RR. Iron metabolism, , 3rd ed. Chichester: Wiley; 2009.

3. Brittenham GM. Iron distribution. In: Hoffman R, Benz E, Shattil S, Furie B, Cohen H, eds. Hematology: basic principles and practice. New York: Churchill Livingstone; 1991. p 327.

4. Hershko C, Konijn AM, Link G. Iron chelators for thalassaemia. $\mathrm{Br} \mathrm{J}$ Haematol 1998;101:399-406.

5. Ma Y, Zhou T, Kong X, Hider RC. Chelating agents for the treatment of systemic iron overload. Curr Med Chem 2012;19:2816-27.

6. Raymond KN, Carrano CJ. Coordination chemistry and microbial iron transport. Acc Chem Res 1979;12:183-90.

7. Tilbrook GS, Hider RC. Metal ions in biological systems: iron transport and storage in microorganisms, plants and animals, vol. 35. New York: Marcel Dekker; 1998. pp 691730 .

8. Fagerholm U, Nilsson D, Knutson L, Lennernas $H$. Jejunal permeability in humans in vivo and rats in situ: investigation of molecular size selectivity and solvent drag. Acta Physiol Scand 1999;165: 315-24.

9. Kim M. Absorption of polyethylene glycol oligomers (330-1122 Da) is greater in the jejunum than in the ileum of rats. J Nutr 1996;126:2172-2178.

10. Hider RC. Potential protection from toxicity by oral iron chelators. Toxicol Lett 1995;823:961-7.

11. Liu ZD, Kayyali RS, Hider RC, Theobald AE. Design, synthesis, and evaluation of novel 2-substituted. 3-hydroxypyridin-4-ones: structure-activity investigation of metalloenzyme inhibition by iron chelators. J Med Chem 2002;45:631-9.

12. Devanur LD, Neubert H, Hider RC. The fenton activity of iron(III) in the presence of deferiprone. J Pharm Sci 2008;97:1454-67. 
13. Hider RC, Kong X. Chemistry and biology of siderophores. Nat Prod Rep 2010;27: 63757.

14. Merkofer M, Kissner R, Hider RC, et al. Fenton chemistry and iron chelation under physiologically relevant conditions: electrochemistry and kinetics. Chem Res Toxicol 2006;19:1263-9.

15. Hershko C, Peto TEA. Non-transferrin plasma iron. Br J Haematol 1987;66:149-51.

16. Silva AMN, Hider RC. Influence of nonenzymatic post-translation modifications on the ability of human serum albumin to bind iron. Implications for non-transferrinbound iron speciation. Biochim Biophys Acta 2009;1794:1449-58.

17. Hider RC, Silva AMN, Podinovskaia M, Ma Y. Monitoring the efficiency of iron chelation therapy: the potential of nontransferrin-bound iron. Annals N Y Acad Sci 2010;1202:94-9.

18. Bullen JJ, Griffiths E. Iron and infection: molecular, physiological, and clinical aspects. New York: Wiley; 1999.

19. Moridani MY, Tilbrook GS, Khodr HH, Hider RC. Synthesis and physicochemical assessment of novel 2-substituted 3-hydroxypyridin-4-ones, novel iron chelators. J Pharm Pharmacol 2002;54:349-64.

20. Martell AE, Motekaitis RJ, Murase I, et al. Development of iron chelators for Cooley's anemia. Inorg Chim Acta 1987;138:215-30.

21. Liu ZD, Hider RC. Design of iron chelators with therapeutic application. Coord Chem Rev 2002;232:151-71.

22. Hider RC, Roy S, Ma YM, et al. The potential application of iron chelators for the treatment of neurodegenerative diseases. Metallomics 2011;3:239-49.

23. Ponka P, Borova J, Neuwirt J, Fuchs 0 . Mobilization of iron from reticulocytes. Identification of pyridoxal isonicotinoyl hydrazone as a new iron chelating agent. FEBS Lett 1979;97:317-21.

24. Hershko C, Avramovici-Grisaru S, Link G, et al. Mechanism of in vivo iron chelation by pyridoxal isonicotinoyl hydrazone and other imino derivatives of pyridoxal. J Lab Clin Med 1981;98:99-108.

25. Baker E, Vitolo ML, Webb JM. Iron chelation by pyridoxal isonicotinoyl hydrazone and analogues in hepatocytes in culture. Biochem Pharmacol 1985;34:3011-7.

26. Richardson DR, Ponka P. Pyridoxal isonicotinoyl hydrazone and its analogs: potential orally effective iron-chelating agents for the treatment of iron overload disease. $\mathrm{J}$ Lab Clin Med 1998;131:306-15.

27. Brittenham GM. Pyridoxal isonicotinoyl hydrazone. Effective iron chelation after oral administration. Ann NY Acad Sci 1990;612:315-26.

28. Hoffbrand AV, Cohen A, Hershko C. Role of deferiprone in chelation therapy for trans- fusional iron overload. Blood 2003;102:1724.

29. Hershko C. Iron chelators in medicine. Mol Aspects Med 1992;13:113-65.

30. Hahn FN, McMurry TJ, Hugi A, Raymond KN. Cr(III) and Co(III) complexes of desferriferrithiocin. J Am Chem Soc 1990;112: 1854-60.

31. Wolfe LC. Desferrithiocin. Sem Hematol 1990;27:117-120.

32. Baker E, Wong A, Peter H, Jacobs A. Desferrithiocin is an effective iron chelator in vivo and in vitro but ferrithiocin is toxic. Br J Haematol 1992;81:424-31.

33. Bergeron RJ, Wiegand J, McManis JS, et al. (S)-4,5-dihydro-2-(2-hydroxy-4-hydroxyphenyl)-4-methyl-4-thiazolecarboxylic acid polyethers: a solution to nephrotoxicity. J Med Chem 2006;49:2772-83.

34. Bergeron RJ, Wiegand J, McManis JS, et al. Effects of C-4 stereochemistry and C-4' hydroxylation on the iron clearing efficiency and toxicity of desferrithiocin analogues. J Med Chem 1999;42:2432-40.

35. Barton JC. Drug evaluation: deferitrin for iron overload disorders. IDrugs 2007;10:480-90.

36. Bergeron RJ, Wiegand J, Bharti N, et al. Desferrithiocin analogue iron chelators: iron clearing efficiency, tissue distribution, and renal toxicity. Biometals 2011;24: 23958.

37. Rienhott HY, Viprakasit V, Tay L, et al. A phase 1 dose-escalation study: safety, tolerability, and pharmacokinetics of FBS0701, a novel oral iron chelator for the treatment of transfusional iron overload. Haematologica 2011;96:521-5.

38. Hider RC, Kong X, Luker T, et al. SPD602 is a selective iron chelator which is able to mobilise the non-transferrin iron pool. Blood 2013;122:1673.

39. Neufeld EJ, Galanello R, Viprakasit V, et al. A phase 2 study of the safety, tolerability, and pharmacodynamics of FBS0701, a novel oral iron chelator, in transfusional iron overload. Blood 2012;119:3263-8.

40. Nick HP, Acklin P, Faller B, et al. A new, potent, orally active, iron chelator. In: Badman DG, Bergeron RJ, Brittenham GM, eds. Iron chelators: new development strategies. The Saratoga Group; 2000. p 311.

41. Lattmann R, Acklin P. Substituted 3,5diphenyl-1,2,4-triazoles and their use as pharmaceutical metal chelators. International Patent WO 97/49395; 1997.

42. Heinz U, Hegetschweiler K, Acklin P, et al. 4-[3,5-Bis(2-hydroxyphenyl)-1,2,4-triazol1-yl]-benzoic acid: a novel efficient and selective iron(III) complexing agent. Angew Chem Int Ed 1999;38:2568-70.

43. Hershko C, Konijn AM, Nick HP, et al. ICL670A: a new synthetic oral chelator: evaluation in hypertransfused rats with selective radioiron probes of hepatocellular and reticuloendothelial iron stores and in iron-loaded rat heart cells in culture. Blood 2001;97:1115-22.

44. Weiss HM, Fresneau M, Camenisch GP, et al. In vitro blood distribution and plasma protein binding of the iron chelator deferasirox (ICL670) and its iron complex fe-[ICL670]2 for rat, marmoset, rabbit, mouse, dog, and human. Drug Metab Dispos 2006;34:971-5.

45. Galanello R, Piga A, Alberti D, et al. Safety, Tolerability, and pharmacokinetics of ICL670, a new orally active iron-chelating agent in patients with transfusion-dependent iron overload due to $\beta$-thalassemia. J Clin Pharmacol 2003;43:565-72.

46. Piga A, Galanello R, Forni GL, et al. Randomized phase II trial of deferasirox (Exjade, ICL670), a once-daily, orallyadministered iron chelator, in comparison to deferoxamine in thalassemia patients with transfusional iron overload. Haematologica 2006;91:873-80.

47. Cappellini MD, Porter J, El-Beshlawy A, et al. Tailoring iron chelation by iron intake and serum ferritin: the prospective EPIC study of deferasirox in 1744 patients with transfusion-dependent anemias. Haematologica 2010;95:557-66.

48. Wood JC, Kang BP, Thompson A, et al. The effect of deferasirox on cardiac iron in thalassemia major: impact of total body iron stores. Blood 2010;116:537-43.

49. Steinhauser S, Heinz U, Bartholomo M, et al. Complex formation of ICL670 and related ligands with $\mathrm{Fe}(\mathrm{III})$ and $\mathrm{Fe}(\mathrm{II})$. Eur J Inorg Chem 2004;4177-92.

50. RyabukhinYI, Shibaeva NV, Kuzharov AS, et al. Synthesis and investigation of complex compounds of transition metals with $\mathrm{Di}(0-$ hydroxyphenyl)-1,2,4-oxadiazole and its 1,2,4 triazole analogs. Sov J Coord Chem (Engl. transl.) 1987;13:493-9.

51. Vichinsky E, Onyekwere 0, Porter J, et al. Deferasirox versus deferoxamine for the treatment of transfusional iron overload in sickle cell disease. $\mathrm{Br} \mathrm{J}$ Haematol 2006;136:501-8.

52. Rafat C, Fakhouri F, Ribeil JA, et al. Fanconi syndrome due to deferasirox. Am J Kidney Dis 2009;54:931-4.

53. Hider RC. Charge states of deferasirox-ferric iron complexes. Am J Kidney Dis 2010;55:614-5.

54. Garrett TM, Miller PW, Raymond KN. Ferric ion sequestering agents. 20. 2,3Dihydroxyterephthalamides: highly efficient iron(III)-chelating agents. Inorg Chem 1989;28:128-33.

55. Hider RC, Kontoghiorghes G, Silver J, Stockham MA. Pharmaceutical compositons. G B Patent 1984;989:21. 
56. Liu ZD, Hider RC. Design of clinically useful iron(III)-selective chelators. Med Res Rev 2002;22:26-64.

57. Turnquist TD, Sandell EB. Stability constants of iron(III)8-hydroxyquinoline complexes. Anal Chim Acta 1968;42:239-45.

58. Tomkinson JC, Williams RJP. Oxidation reduction potentials of complex ions. J Chem Soc 1958;2010-8.

59. Oakley GP. The neurotoxicity of the habgenated hydroxyquinolines. JAMA 1973; 225:395-7.

60. Kontoghiorghes G, Aldouri MA, Hoffbrand AV. Effective chelation of iron in beta thalassaemia with the oral chelator 1,2dimethyl-3-hydroxypyrid-4-one. Br Med J 1987;295:1509-12.

61. Maggio A, Amico GD, Morabito A, et al. Deferiprone versus deferoxamine in patients with thalassemia major: a randomized clinical trial. Blood Cells Mol Dis 2002;28:196-208.

62. Hoffbrand AV, Cohen A, Hershko C. Role of deferiprone in chelation therapy for transfusional iron overload. Blood 2003;102:1724.

63. Glickstein H, Ben El R, Link G, et al. Action of chelators in iron-loaded cardiac cells: accessibility to intracellular labile iron and functional consequences. Blood 2006;108: 3195-203.

64. Pennell DJ, Berdoukas V, Karagiorga M, et al. Randomized controlled trial of deferiprone or deferoxamine in beta-thalassemia major patients with asymptomatic myocardial siderosis. Blood 2006;107:373844.

65. Hershko C, Cappellini MD, Galanello R, et al. Purging iron from heart. Br J Haematol 2004;125:545-51.

66. Pepe A, Meloni A, Capra M, et al. Deferasirox, deferiprone and desferrioxamine treatment in thalassemia major patients: cardiac iron and function comparison determined by quantitative magnetic resonance imaging. Haematologica 2011; 96:41-7.

67. Balfour AB, Foster RH. A review of its clinical potential in iron overload in $\beta$-thalassaemia major and other transfusion-dependent diseases. Drugs 1999;58:553-78.

68. Singh S, Epemolu 0, Dobbin PS, et al. Urinary metabolic profile in human and rat of 1,2-dimethyl and 1,2-diethyl substituted 3-hydroxypyridin-4-ones. Drug Metab Dispos 1992;20:256-61.

69. Cohen A, Galanello R, Piga A, et al. Safety and effectiveness of long-term therapy with the oral iron chelator deferiprone. Blood 2003;102:1583-7.

70. Ceci A, Baiardi P, Felisi M, et al. The safety and effectiveness of deferiprone in a largescale 3-year study in italian patients. Br J Haematol 2002;118:330-6.

71. Hoffbrand AV, Wonke B. Iron chelation therapy. J Internal Med 1997;242:37-41.

72. Srichairatanakool S, Pangjit K, Phisalaphong C, et al. Evaluation of a novel oral iron chelator 1-(N-acetyl-6-aminohexyl)-3-hydroxypyridin-4-one (CM1) for treatment of iron overload in mice. Adv Biosci Biotech 2013;4:153-63.

73. Hider RC, Tilbrook GS, Liu ZD. Novel orally active iron(III) chelators. International Patent WO 98/54138; 1998.

74. Lowther N, Fox P, Faller B, et al. Structureactivity relationships among desazadesferrithiocin analogues. Pharmaceut Res 1999;16:434-40.

75. Sergejew T, Forgiarini P, Schnebli HP. Chelator-induced iron excretion in ironoverloaded marmosets. Br J Haematol 2000;110:985-92.

76. Liu ZD, Khodr HH, Liu DY, et al. Synthesis, physiochemical characterisation and biological evaluation of 2-(1'-Hydroxyalkyl)3-hydroxypyridin-4-ones: novel Iron Chelators with Enhanced $\mathrm{pFe}^{3+}$ values. J Med Chem 1999;42:4814-23.

77. Piyamongkol S, Ma YM, Kong XL, et al. Amido-3-hydroxypyridin-4-ones as iron(III) ligands. Chem Eur J 2010;16:6374-81.

78. Devanur LD, Evans RW, Evans PJ, Hider RC. Chelator-facilitated removal of iron from transferrin: relevance to combined chelation therapy. Biochem J 2008;409:439-41.

79. Evans RW, Kong X, Hider RC. Iron mobilization from transferrin by therapeutic iron chelating agents. Biochim Biophys Acta 2012;1820:282-90.

80. Evans P, Kayyali R, Hider RC, et al. Mechanisms for the shuttling of plasma non-transferrin-bound iron (NTBI) onto deferoxamine by deferiprone. Translational Res 2010;156:55-61.

81. Wonke B, Wright C, Hoffbrand AV.
Combined therapy with deferiprone and desferrioxamine in thalassemia major. Br $\mathrm{J}$ Haematol 1998;103:361-4.

82. Giardina PJ, Grady RW. Chelation therapy in $\beta$-thalassemia: an optimistic update. Sem Hematol 2001;38:360-6.

83. Piga A, Gaglioti C, Fogliacco E, Tricta F. Comparative effects of deferiprone and deferoxamine on survival and cardiac disease in patients with thalassemia major: a retrospective analysis. J Hematology 2003;88:489-96.

84. Maggio A, Vitrano A, Capra M, et al. Longterm sequential deferiprone-deferoxamine versus deferiprone alone for thalassaemia major patients: a randomized clinical trial. Br J Haematol 2009;145:245-54.

85. Lai ME, Grady RW, Vacquer S, et al. Increased survival and reversion of ironinduced cardiac disease in patients with thalassemia major receiving intensive combined chelation therapy as compared to desferoxamine alone. Blood Cells Mol Dis 2010;45:136-43.

86. Galanello R, Agus A, Campus S, et al, Combined iron chelation therapy. Annals N Y Acad Sci 2010;120:79-86.

87. Farmaki K, Tzoumari I, Pappa C, et al. Normalisation of total body iron load with very intensive combined chelation reverses cardiac and endocrine complications of thalassaemia major. Br J Haematol 2010;148: 466-75.

88. Berdoukas V, Chouliaras G, Moraitis P, et al. The efficacy of iron chelator regimes in reducing cardiac and hepatic iron in patients with thalassaemia major: a clinical observational study. J Cardiovasc Magn Reson 2009;28:11-20.

89. Voskaridou E, Christoulas D, Terpos E. Successful chelation therapy with the combination of deferasirox and deferiprone in a patient with thalassaemia major and persisting severe iron overload after singleagent chelation therapies. Br J Haematol 2011;154:654-6.

90. Nurchi VM, Crisponi G, Pivetta T, et al. Potentiometric, spectrophotometric and calorimetric study on iron(III) and copper(II) complexes with 1,2-dimethyl-3hydroxy-4-pyridinone. J Inorg Biochem 2008;102:684-92. 